\title{
The New Sugar to Suppress Postprandial Hyperglycemia: Improvement of Refined White Sugar by Mixing Specially Grown Brown Cane Extract
}

\section{Tsutomu Arimura ${ }^{1}$, Shaw Watanabe ${ }^{2 *}$, Hiroyuki Sakakibara ${ }^{3}$ and Shigekatsu Kimura ${ }^{1}$}

${ }^{1}$ Daito Seito Co, Ltd., Japan

${ }^{2}$ Tokyo University of Agriculture, Japan

${ }^{3}$ University of Miyazaki, Japan

*Corresponding Author: Shaw Watanabe, Tokyo University of Agriculture, Japan.
Received: April 21, 2021

Published: May 24, 2021

(C) All rights are reserved by Shaw Watanabe., et al.

\begin{abstract}
The minimal refining process of sugarcane extract retained some of its phytochemicals, vitamins, and minerals. The addition of this extract to the refined brown sugar lowered glycemic index (GI) and suppress postprandial hyperglycemia. A quick squeeze of sugar cane and quick processing caused a considerable amount of antioxidants (polyphenols). Overall, low postrandial (LP) sugar had a better nutritional quality in terms of physicochemical characteristics and health benefits.
\end{abstract}

Keywords: New Sugar; LP Sugar; GI; Brown Sugar; Postprandial Hyperglycemia

\section{Introduction}

Adverse effects of refined white sugar have been well recognized, and WHO recommends not to take more than $10 \mathrm{~g}$ a day $[1,2]$. However, its consumption remains high because of its gustative, nutritional, and preservative properties that make it an essential nutrient.

Tissues, such as the brain, nervous tissue, red blood cells, and skeletal muscle, can only use glucose as an energy source. Among them, the brain is thought to consume about $20 \%$ of the basal metabolic rate. If the basal metabolism is $1500 \mathrm{kcal} /$ day, it is equivalent to $300 \mathrm{kcal} /$ day (glucose $75 \mathrm{~g} /$ day). In addition of brain, many other tissues also use glucose as energy source, therefore, at least $100 \mathrm{~g} /$ day of sugar is required for people to live.

Refined sugar is made by sequential process: washing, extraction, purification, crystallization, drying, and packaging [3]. The high purity of refined sugar, however, its nutritional value is low, and it provides empty calories. Unrefined brown sugar has a low glycemic index (GI) which may prevent hyperglycemia. Recent studies reveal the risk of postprandial hyperglycemia is more critical by a human study and predictive factor of cardiovascular diseases [4].

Brown sugar comprises $88 \%$ to $93 \%$ of sucrose, but it has a unique flavor and smell due to predominant phytochemicals $[5,6]$. Sugar cane juice contains rich flavonoids (apigenin, luteolin, and tricin derivatives) and many phenolic acids, such as hydroxycinnamic acid, caffeic acid, and sinapic acid $[7,8]$. These are considered to be functional ingredients $[9,10]$.

Usually, brown sugar has higher amounts of phenolics than refined sugar. For instance, the total phenolic content of brown sugar ranges from $108.1 \mu \mathrm{g}$ to $259.6 \mu \mathrm{g}$ gallic acid equivalent (GAE)/g 
sample [5]. Phytochemicals may play an essential role in maintaining physical health.

We developed a mixture of refined brown sugar and flesh sugar cane extract, which lowered GI and prevented postprandial hyperglycemia. We named this new sugar as LP (low postprandial) sugar.

Health professionals recommend increasing the intake of foods rich in antioxidants. Raw brown sugar extract may offer a potential extra health benefit source in this regard. We succeeded to improve the nutritional properties of refined brown sugar by adding the specially grown brown cane extract and confirmed the suppressive effects on postprandial hyperglycemia.

\section{Materials and Methods}

Our sugar cane farm on Tanegashima island grows species of sugar cane, Kurokaido and Norin 22, which fit the Japanese soil and climate. According to WHO standards, raw sugar extract is directly produced from food-grade sugar mills aside from our sugar cane farm by a sequential process involving washing raw materials, extraction, and minimal refining. These processed in one day to keep flesh and preserve functional factors.

The quick and fewer processes involved in producing raw sugar cane extract retained some naturally occurring trace minerals (such as calcium, magnesium, and potassium), vitamins, amino acids, antioxidants, and phytochemicals.

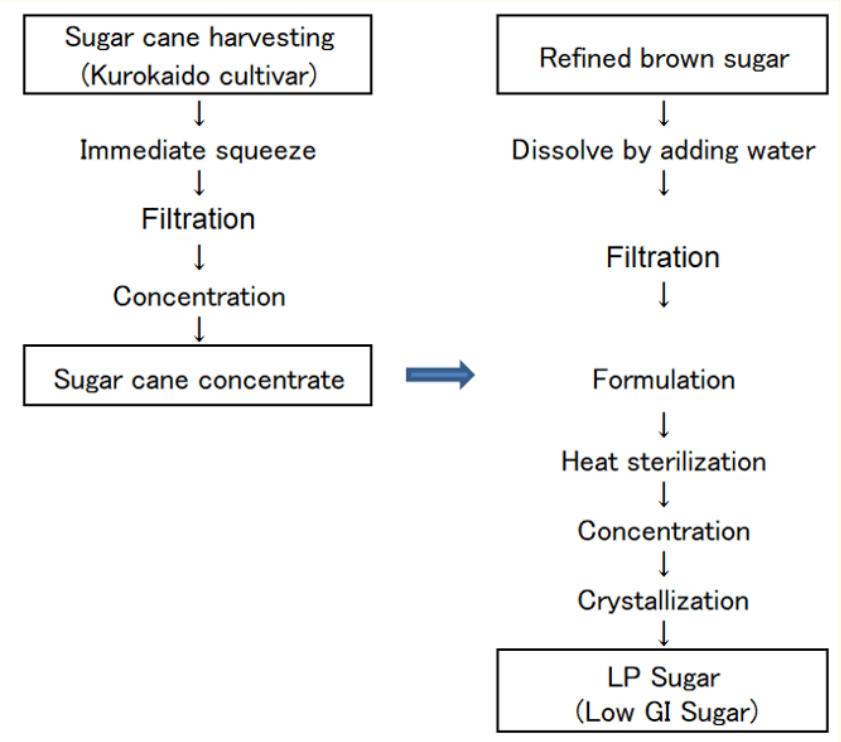

Figure 1: Schema of processing LP sugar. Blue arrow shows a mixing process.
We used partially refined brown sugar from Australian refined brown sugar.

Then, concentrated raw sugar cane extract was added at a rate of $2 \%$ to the refined sugar after detecting metal contamination. Addition of $1 \%$ was less effective, and $2 \%$ or more did not cause additional benefit and the taste of brown sugar remained.

\section{Determination of nutrients}

Nutrients and functional ingredients were measured at the Japan Food Chemicals Analyzing Center and SUNTEC, Japan.

\section{Determination of glycemic index}

Ten normal, healthy subjects were recruited voluntarily to participate in the study. Before the tolerance test, all subjects received a health check-up. The Minamimachi Clinic obtained the study's ethical approval, and all subjects gave the written informed consent to participate.

Three separate tolerance tests were performed in the morning after a 10 - $12 \mathrm{~h}$ overnight fasting. After a fasting blood sampling, subjects drank a test glucose $50 \mathrm{~g}$ in $200 \mathrm{ml}$ water at a comfortable pace within 5 min and had further blood samples at 15, 30, 45, 60, 90 , and $120 \mathrm{~min}$ after the start. Test drink of LP sugar contained same amount of glucose, and was served with water as well.

Blood could be obtained by finger-prick and whole blood glucose measured by the Abbott glucose sensor. The blood sampling method and glucose measurement remained standard for the duration of the study plasma glucose measured by a hexokinase method.

\section{Statistical analysis}

All analyses were conducted double for each sugar sample. IBMSPSS version 24 was used for statistical analysis. Significant differences between the mean values of the pieces were statistically analyzed using paired analysis. Mean and s.d. of biochemical and other physical data by sex were calculated. The significance level was set at $\mathrm{p}<0.05$.

\section{Results and Discussion \\ Determination of Nutrients, vitamins, and minerals}

The nutrient contents of refined brown sugar, sugar cane extract and LP sugar are shown in table 1 . Carbohydrate content was 98.4, 70.4, and 98.2, respectively. Most of them were sucrose (96.6\%), but a small amount of glucose and fructose were present. High protein content $(0.9 \%)$ and ash $(2.1 \%)$ were characteristic of sugar cane extract. 


\begin{tabular}{|c|c|c|c|c|}
\hline Name & $/ 100 \mathrm{~g}$ & Brown sugar & $\begin{array}{l}\text { Sugar Cane } \\
\text { Extract }\end{array}$ & LP Sugar \\
\hline Energy & kcal & 398 & 276 & 383 \\
\hline water & $g$ & 0.2 & 26.6 & 1.4 \\
\hline Carbohydrate & g & 99.6 & 70.4 & 98.2 \\
\hline sucrose & g & 96.6 & 52.7 & 96.6 \\
\hline glucose & $\mathrm{g}$ & na & na & 0.5 \\
\hline fructose & g & na & na & 0.4 \\
\hline Protein & g & $<0.01$ & 0.9 & 0.1 \\
\hline Lipid & g & $<0.01$ & $<0.01$ & $<0.01$ \\
\hline Ash & g & 0.5 & 2.1 & 0.3 \\
\hline Polyphenol & $\mathrm{g}$ & $\begin{array}{lll}- & \\
-\end{array}$ & - & 0.09 \\
\hline ORAC total & umole TE/g & 14 & 55 & 16 \\
\hline ORAC hydrophilic & umole $\mathrm{TE} / \mathrm{g}$ & 14 & 55 & 16 \\
\hline ORAC lipophilic & umole $T E / g$ & nd & nd & nd \\
\hline $\mathrm{Na}$ & $\mathrm{mg}$ & 30.8 & 9.0 & 18.3 \\
\hline $\mathrm{NaCl}$ eq & $\mathrm{g}$ & 0.0780 & 0.023 & 0.0470 \\
\hline $\mathrm{K}$ & $\mathrm{mg}$ & 162 & 914 & 100 \\
\hline $\mathrm{Ca}$ & $\mathrm{mg}$ & 41.4 & 32.1 & 28.9 \\
\hline $\mathrm{Mg}$ & $\mathrm{mg}$ & 13.7 & 45.9 & 11.4 \\
\hline $\mathrm{Fe}$ & $\mathrm{mg}$ & 0.62 & 0.40 & 0.41 \\
\hline $\mathrm{Cu}$ & $\mathrm{mg}$ & 0.02 & 0.04 & 0.02 \\
\hline $\mathrm{Zn}$ & $\mathrm{mg}$ & nd & nd & nd \\
\hline $\mathrm{Mn}$ & $\mathrm{mg}$ & 0.22 & 0.23 & 0.24 \\
\hline Mo & $\mu g$ & nd & nd & nd \\
\hline $\mathrm{Se}$ & $\mu g$ & nd & nd & nd \\
\hline $\mathrm{P}$ & $\mathrm{mg}$ & 4.2 & 30.7 & 3.8 \\
\hline 1 & $\mu g$ & nd & nd & nd \\
\hline $\mathrm{Cr}$ & $\mu g$ & nd & nd & nd \\
\hline $\mathrm{As}_{2} \mathrm{O}_{3}$ & $\mathrm{ppm}$ & nd & nd & nd \\
\hline $\mathrm{Pb}$ & $\mathrm{ppm}$ & nd & nd & 0.02 \\
\hline $\mathrm{Cd}$ & $\mathrm{ppm}$ & nd & nd & - \\
\hline $\mathrm{Hg}$ & $\mathrm{ppm}$ & nd & nd & - \\
\hline Bacilli & $n / g$ & $<300$ & $<300$ & $<300$ \\
\hline Coli & & negative $/ 2.22 \mathrm{~g}$ & negative $/ 0.1 \mathrm{~g}$ & negative $/ 0.1 \mathrm{~g}$ \\
\hline 0157 & & - & - & negative \\
\hline Fungus & $/ 0.1 \mathrm{~g}$ & negative & negative & negative \\
\hline Yeast & $0.1 \mathrm{~g}$ & negative & negative & negative \\
\hline Spore & $\mathrm{n} / \mathrm{g}$ & $<300$ & $<300$ & $<300$ \\
\hline Staphylococcus & $/ 0.01 \mathrm{~g}$ & negative & negative & negative \\
\hline Salmonella & $/ 25 \mathrm{~g}$ & negative & negative & negative \\
\hline Bacillus cereus & $0.01 \mathrm{~g}$ & negative & negative & negative \\
\hline Clostrodia & $\mathrm{n} / \mathrm{g}$ & - & negative & negative \\
\hline
\end{tabular}

Table 1: Ingredients of raw sugar, sugar cane extract, and new sugar.

Mineral contents were correlated with ash content. LP sugar had a rich ash content $(0.3 \mathrm{~g} / 100 \mathrm{~g})$. Potassium, calcium, and magnesium were high in sugar cane extract, as well as brown sugar. Other minerals, such as $\mathrm{Zn}, \mathrm{Se}, \mathrm{Cr}$, Mo, and I, were not detected. Toxic $\mathrm{As}, \mathrm{Cd}, \mathrm{Pb}$, and $\mathrm{Hg}$ were not present. Bacilli, fungus, and yeast were not present.

The polyphenol contents of LP sugar were determined following the Folin-Ciocalteu method. Results showed that sugar cane extract (240 mg GAE/100 g sample) had the highest, and LP sugar followed (90 mg GAE/100 g sample).

Amino acids were not remarkable except for aspartic acid (28 $\mathrm{mg} / 100 \mathrm{~g}$ ) (Table 2).

\section{Glucose intolerent test}

The average age of the participants was $35.8 \pm 10.5$ years in males and $39.1 \pm 10.1$ years in females (Table 3 ). Systolic and diastolic blood pressure were within a standard range, and pulse and body temperature were also in the normal range.

Laboratory data of participants were shown in table 4.

\begin{tabular}{|l|c|c|}
\hline \multicolumn{3}{|c|}{ Aminoacid contents in LP sugar } \\
\hline Arginine & $\mathrm{mg}$ & nd \\
\hline Lysin & $\mathrm{mg}$ & nd \\
\hline Histidine & $\mathrm{mg}$ & $\mathrm{nd}$ \\
\hline Phenylalanine & $\mathrm{mg}$ & 1 \\
\hline Tyrosin & $\mathrm{mg}$ & $\mathrm{nd}$ \\
\hline Lysin & $\mathrm{mg}$ & 2 \\
\hline Isoleucine & $\mathrm{mg}$ & 1 \\
\hline Methionine & $\mathrm{mg}$ & $\mathrm{nd}$ \\
\hline Valine & $\mathrm{mg}$ & 3 \\
\hline Proline & $\mathrm{mg}$ & 2 \\
\hline Glutaminic acid & $\mathrm{mg}$ & 9 \\
\hline Seline & $\mathrm{mg}$ & 2 \\
\hline Threonine & $\mathrm{mg}$ & 2 \\
\hline Asparatic acid & $\mathrm{mg}$ & 28 \\
\hline Tryptophan & $\mathrm{mg}$ & $\mathrm{nd}$ \\
\hline Cystine & $\mathrm{mg}$ & $\mathrm{nd}$ \\
\hline Hydroxyproline & $\mathrm{mg}$ & $\mathrm{nd}$ \\
\hline
\end{tabular}

Table 2: Amino acids content in LT sugar. 


\begin{tabular}{|l|c|c|c|c|c|c|}
\hline & \multicolumn{2}{|c|}{ Male n 4 } & \multicolumn{2}{c|}{ Female $\mathbf{n = 6}$} & \multicolumn{2}{c|}{ Total n= 10 } \\
\hline & Mean & SD & Mean & SD & Mean & SD \\
\hline Age & 35.8 & 10.5 & 39.1 & 10.1 & 37.8 & 9.9 \\
\hline Sys BP & 120.7 & 12.5 & 109.5 & 13.2 & 114.0 & 13.9 \\
\hline Dia BP & 82.3 & 13.7 & 69.1 & 9.2 & 74.4 & 12.8 \\
\hline Pulse & 77.3 & 15.3 & 74.1 & 8.8 & 75.4 & 11.7 \\
\hline Temp & 33.3 & 0.8 & 33.3 & 0.8 & 33.3 & 0.8 \\
\hline
\end{tabular}

Table 3: Anthropometric data of participants.

\begin{tabular}{|c|c|c|c|c|c|c|c|}
\hline & \multirow[b]{2}{*}{ Unit } & \multicolumn{2}{|c|}{ Male $n=4$} & \multicolumn{2}{|c|}{ Female $n=6$} & \multicolumn{2}{|c|}{ Total $n=10$} \\
\hline & & Mean & SD & Mean & SD & Mean & SD \\
\hline Age & Year & 35.8 & 10.8 & 39.2 & 10.1 & 37.8 & 9.9 \\
\hline BMI & $\mathrm{kg} / \mathrm{m}^{2}$ & 21.9 & 2.5 & 21.9 & 3.5 & 21.9 & 3.0 \\
\hline WBC & $/ \mathrm{mm}^{3}$ & 5200.0 & 1134.3 & 6000.0 & 2773.4 & 5680.0 & 2207.5 \\
\hline RBS & $104 / \mathrm{mm}^{3}$ & 507.5 & 7.0 & 440.7 & 44.3 & 467.4 & 47.9 \\
\hline $\mathrm{HB}$ & $\mathrm{g} / \mathrm{dl}$ & 15.4 & 1.0 & 12.7 & 0.9 & 13.8 & 1.7 \\
\hline HT & $\%$ & 47.1 & 2.5 & 40.8 & 3.2 & 43.3 & 4.3 \\
\hline $\mathrm{PL}$ & $104 / \mathrm{dl}$ & 25.5 & 3.5 & 25.3 & 9.1 & 25.4 & 7.0 \\
\hline PMN & $\%$ & 60.8 & 3.4 & 59.9 & 10.0 & 60.3 & 7.8 \\
\hline Lymph & $\%$ & 31.2 & 4.2 & 33.0 & 8.6 & 32.3 & 6.9 \\
\hline Mono & $\%$ & 5.1 & 1.8 & 5.3 & 1.8 & 5.3 & 1.7 \\
\hline Eosino & $\%$ & 2.4 & 1.7 & 1.3 & 0.7 & 1.7 & 1.2 \\
\hline Baso & $\%$ & 0.6 & 0.4 & 0.5 & 0.2 & 0.5 & 0.3 \\
\hline Amylase & Unit & 76.3 & 11.5 & 74.5 & 25.9 & 75.2 & 20.5 \\
\hline Glucose & $\mathrm{mg} / \mathrm{dl}$ & 82.0 & 5.0 & 86.0 & 10.5 & 84.4 & 8.6 \\
\hline HbA1c & $\%$ & 5.4 & 0.1 & 5.4 & 0.2 & 5.4 & 0.2 \\
\hline glu_alb & $\%$ & 13.1 & 1.3 & 15.4 & 1.2 & 14.5 & 1.7 \\
\hline protein & $\mathrm{g} / \mathrm{dl}$ & 7.3 & 0.3 & 7.0 & 0.2 & 7.2 & 0.3 \\
\hline BUN & $\mathrm{mg} / \mathrm{dl}$ & 12.6 & 1.3 & 10.0 & 3.0 & 11.0 & 2.7 \\
\hline tot_chol & $\mathrm{mg} / \mathrm{dl}$ & 218.8 & 10.8 & 191.3 & 34.4 & 202.3 & 29.9 \\
\hline HDL & $\mathrm{mg} / \mathrm{dl}$ & 46.3 & 6.7 & 66.0 & 13.5 & 58.1 & 14.8 \\
\hline LDL & $\mathrm{mg} / \mathrm{dl}$ & 143.0 & 6.8 & 108.7 & 22.0 & 122.4 & 24.5 \\
\hline TG & $\mathrm{md} / \mathrm{dl}$ & 147.8 & 87.6 & 81.3 & 55.0 & 107.9 & 73.6 \\
\hline AST & Unit & 20.8 & 5.4 & 16.0 & 1.4 & 17.9 & 4.1 \\
\hline ALT & Unit & 23.0 & 15.4 & 10.7 & 2.3 & 15.6 & 11.1 \\
\hline$\gamma-\mathrm{GT}$ & Unit & 31.5 & 19.6 & 15.7 & 8.4 & 22.0 & 15.3 \\
\hline ALP & & 257.5 & 62.3 & 147.0 & 39.7 & 191.2 & 73.7 \\
\hline LD & & 174.5 & 35.7 & 162.0 & 8.4 & 167.0 & 22.5 \\
\hline
\end{tabular}




\begin{tabular}{|l|c|c|c|c|c|c|c|}
\hline LAP & & 53.5 & 6.0 & 48.8 & 5.0 & 50.7 & 5.6 \\
\hline tot_bil & & 1.0 & 0.2 & 0.8 & 0.2 & 0.9 & 0.2 \\
\hline dir_bil & & 0.1 & 0.0 & 0.1 & 0.1 & 0.1 & 0.0 \\
\hline Indirect bil & & 0.9 & 0.2 & 0.7 & 0.2 & 0.8 & 0.2 \\
\hline $\mathrm{Cr}$ & $\mathrm{mg} / \mathrm{dl}$ & 0.9 & 0.1 & 0.6 & 0.1 & 0.7 & 0.2 \\
\hline $\mathrm{UA}$ & $\mathrm{mg} / \mathrm{dl}$ & 5.9 & 0.3 & 4.1 & 1.2 & 4.8 & 1.3 \\
\hline $\mathrm{CK}$ & $\mathrm{mg} / \mathrm{dl}$ & 122.8 & 22.0 & 76.0 & 23.3 & 94.7 & 32.3 \\
\hline $\mathrm{Na}$ & $\mathrm{mg} / \mathrm{dl}$ & 140.3 & 1.3 & 138.7 & 1.2 & 139.3 & 1.4 \\
\hline $\mathrm{K}$ & $\mathrm{mg} / \mathrm{dl}$ & 4.0 & 0.3 & 4.1 & 0.2 & 4.0 & 0.2 \\
\hline $\mathrm{Cl}$ & $\mathrm{mg} / \mathrm{dl}$ & 99.8 & 0.5 & 101.0 & 1.1 & 100.5 & 1.1 \\
\hline $\mathrm{Ca}$ & $\mathrm{mg} / \mathrm{dl}$ & 9.4 & 0.3 & 9.0 & 0.3 & 9.2 & 0.3 \\
\hline $\mathrm{P}$ & $\mathrm{mg} / \mathrm{dl}$ & 3.1 & 0.3 & 3.3 & 0.4 & 3.2 & 0.4 \\
\hline $\mathrm{Fe}$ & $\mathrm{ug} / \mathrm{dl}$ & 121.3 & 27.3 & 91.2 & 28.2 & 103.2 & 30.5 \\
\hline
\end{tabular}

Table 4: Laboratory data of participants by sex.

In both males and females, the subjects were middle-aged healthy subjects with BMI $21.9 \mathrm{~kg} / \mathrm{m}^{2}$. Hematological tests were all within normal range with adequate hemogram.

Their fasting glucose level was $82 \pm 5$ in males and $86 \pm 10.5$ $\mathrm{mg} / \mathrm{dl}$ in females.

HbA1c was $5.4 \pm 0.1 \%$ in males and $5.4 \pm 0.2 \%$ in females. Glucoalbumin was $13.1 \pm 1.3 \%$ in males and $15.4 \pm 1.2 \%$ in females. TG, LDL, and total cholesterol were slightly high among males. Gamma GTP and ALP were also high among males.

\section{Postprandial glucose level}

In this study, post-challenge glucose spikes were defined as the difference between the maximal post-challenge glucose level during OGTT, irrespective of the time after glucose challenge and the level of fasting plasma glucose [9].

Measured GTT and LP sugar level by time are shown in table 5. GI of LP sugar was $52.9 \pm 12.7$. Changes in glucose level by time are shown in figure 2. LP sugar suppressed the glucose level, especially after $60 \mathrm{~min}$.

\begin{tabular}{|l|c|c|c|c|c|c|}
\hline & \multicolumn{2}{|c|}{$1^{\text {st }}$ OGTT } & \multicolumn{2}{c|}{$2^{\text {nd }}$ OGTT } & \multicolumn{2}{c|}{ LP sugar } \\
\hline & Mean & SD & Mean & SD & Mean & SD \\
\hline glu0 & 93.6 & 6.5 & 100.3 & 7.7 & 103.3 & 7.8 \\
\hline glu15 & 139.0 & 14.7 & 133.2 & 18.4 & 145.8 & 19.1 \\
\hline glu30 & 155.9 & 24.1 & 175.3 & 25.0 & 155.5 & 27.9 \\
\hline glu45 & 162.2 & 43.4 & 181.6 & 33.7 & 152.8 & 40.2 \\
\hline glu60 & 163.9 & 47.2 & 177.8 & 45.7 & 144.2 & 31.3 \\
\hline glu90 & 141.2 & 28.7 & 152.0 & 36.2 & 121.8 & 10.7 \\
\hline glu120 & 132.7 & 22.4 & 137.8 & 29.6 & 101.4 & 17.7 \\
\hline IAUCg1 & 104.0 & 38.6 & 111.6 & 37.9 & 61.6 & 20.6 \\
\hline GI & & & & & 52.9 & 12.7 \\
\hline
\end{tabular}

Table 5: Blood glucose level after $50 \mathrm{~g}$ glucose tolerance test and that of LT sugar.

\section{Discussion}

Preference for sweet is the essential desire of obese and diabetic people. Importance is the prevention of complications, like cardiovascular events. 


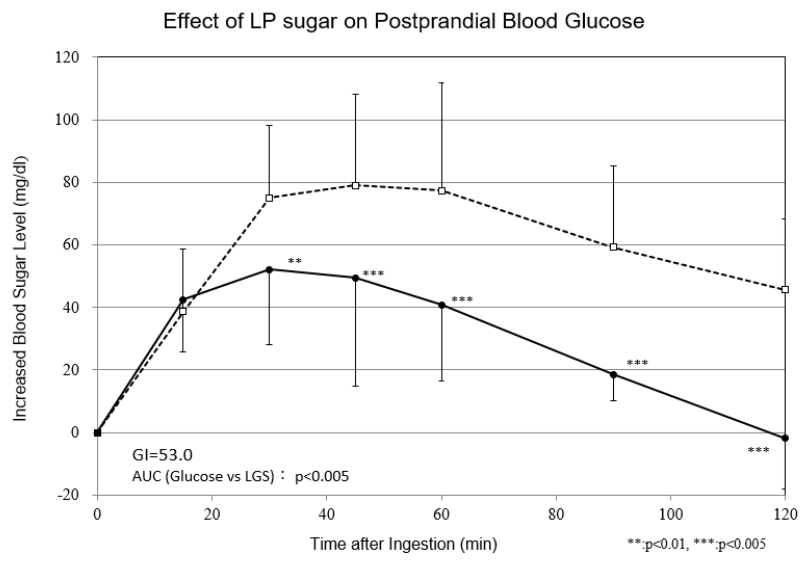

Figure 2: Comparison of new sugar vs. glucose on postprandial glucose level. Dot line; glucose, solid line; LP sugar.

\begin{tabular}{|l|c|c|}
\hline \multicolumn{1}{|c|}{ ID } & Glucose & LP sugar \\
\hline 53731 & 74 & 44 \\
\hline 53732 & 135 & 73 \\
\hline 53735 & 73 & 48 \\
\hline 53736 & 91 & 69 \\
\hline 53737 & 90 & 62 \\
\hline 53740 & 83 & 44 \\
\hline 53741 & 154 & 108 \\
\hline 53743 & 113 & 76 \\
\hline 53744 & 58 & 67 \\
\hline 53758 & 100 & 74 \\
\hline Average & 97.1 & 66.5 \\
\hline
\end{tabular}

Table 6: Individual difference of postprandial glycemia (mg/dl) by glucose or LP sugar.

Many studies [11-13] have clearly shown that the glucose serum level $2 \mathrm{~h}$ after an oral challenge with glucose is a powerful predictor of cardiovascular risk. Two important meta-analyses also confirm this evidence. The first, by Coutinho., et al. [11], examined studies on 95,783 subjects. The second, which involved 20,000 subjects, pooled the Whitehall Study, Paris Prospective Study, and Helsinki
Policemen Study [12]. A 33-yr follow-up of the Whitehall study in which a 50g OGTT was performed at baseline in 1967-1969 in 17869 male civil servants aged 40 - 64 years reported a threshold model with a linear slope as best describing the relationship between 2-h post-load blood glucose and mortality risk.

The possible role of postprandial hyperglycemia as an independent risk factor has also been supported by the Diabetes Intervention Study, which showed how postprandial hyperglycemia predicts infarction in type 2 diabetic subjects [13].

In diabetes, the postprandial phase is characterized by a rapid increase in blood glucose levels. The postprandial state is a contributing factor to the development of atherosclerosis. The postprandial "hyperglycemic spikes" may be relevant to the onset of cardiovascular complications. Cardiovascular events appeared to increase linearly with 2-h post-challenge plasma glucose without a threshold. In contrast, there was a possible threshold for fasting plasma glucose at $5.5 \mathrm{mmol} / \mathrm{l}(100 \mathrm{mg} / \mathrm{dl})$.

For ischaemic heart disease death for fasting glucose, the hazards ratio was best modeled by a positive linear relationship. Still, for 2-h glucose, it was modeled by a J-shaped curve, and the lowest observed death rate was in the interval centered on $6.0 \mathrm{mmol} / \mathrm{l}$ (108 mg/dl).

Epidemiological and intervention studies have shown that postprandial hyperglycemia is a direct and independent risk factor for cardiovascular disease (CVD). The STOP-NIDDM trial has presented data indicating that treatment of subjects with impaired glucose tolerance with the $\alpha$-glucosidase inhibitor acarbose, a compound that specifically reduces postprandial hyperglycemia, was associated with risk reduction in the development of new cases of hypertension and a 49\% risk reduction in cardiovascular events [14].

To decrease the postprandial hyperglycemia, the glycemic index (GI) could alternatively be employed, but GI has a significant within-subject variation of blood glucose responses [15]. Besides, GI was determined by individual food, so its health effects are still in debate.

LP sugar is a good choice of sweetener for prediabetic and diabetic patients. Previous studies suggested that a high ash content is attributed to a high potassium content, which may impart an un- 
pleasant taste and hinder sugar crystallization [16]. In the present study, the sugar ash contents were relatively high, but it did not impair the tasteful sweetness.

LP sugar is also rich in potassium, which has antihypertensive effects. Unrefined sugars retain large amounts of phenolic and flavonoid compounds from sugarcane juice. The contents of phenolics, flavonoids, and other compounds are usually responsible for the dark coloration of brown sugars $[7,8]$.

The mechanisms through which acute hyperglycemia exerts its effects may be identified in the production of free radicals. The harmful impact of postprandial hyperglycemia on diabetes complications has been sufficient to influence key professional guidelines. Correcting postprandial hyperglycemia may form part of the strategy for preventing and managing CVDs in diabetes. The antioxidant activity of LP sugar is helpful for this purpose $[17,18]$.

Our LP sugar showed the characteristic suppression of postprandial glycemia compared to glucose or ordinary brown sugar. The suppression of late absorption at $90 \mathrm{~min}$ to $120 \mathrm{~min}$ suggested the inhibitory action of acarbose. It may need further study to confirm this.

\section{Conclusion}

The quick and minimal refining process of sugarcane extract retained some of its phytochemicals, vitamins, and minerals. An immediate squeeze of sugar cane and quick processing caused a considerable amount of antioxidants (polyphenols). The addition of this extract to the refined brown sugar lowered GI and suppress postprandial hyperglycemia. Overall, LP sugar had a better nutritional quality in terms of physicochemical characteristics and satisfy people who are difficult to restrict sugar intake.

\section{Acknowledgment}

The authors acknowledge the volunteers who participated in the study.

\section{Funding}

Daito-seito Co., Ltd. Supported the study.

\section{Conflict of Interest}

Arimura and Kimura are working in the Daito-seito Co. Ltd. Watanabe and Sakakibara had no conflict of interest to declare.

\section{Bibliography}

1. "Diet, nutrition and the prevention of chronic diseases: report of a Joint WHO/FAO Expert Consultation". WHO Technical Report Series, No. 916. Geneva: World Health Organization (2003).

2. WHO. "Guideline: Sugars intake for adult and children". Geneva, World Health Organization (2015).

3. Jaffé W R. "Nutritional and functional components of non-centrifugal cane sugar: A compilation of the data from the analytical literature". Journal of Food Composition and Analysis 43 (2015): 194-202.

4. Ceriello A., et al. "Postprandial hyperglycemia and diabetes complications Is it time to treat?" Perspectives for Diabetes 54.1 (2005): 1-7.

5. Payet B., et al. "Comparison of the concentrations of phenolic constituents in cane sugar manufacturing products with their antioxidant activities". Journal of Agricultural and Food Chemistry 54 (2006): 7270-7276.

6. Lopes and Borges. Proposal of Standard and Speciation of Brown Sugar, Rapadura and Cane Molasses, (2004).

7. Duarte-Almeida J M., et al. "Antioxidant activity of phenolics compounds from sugar cane (Saccharum officinarum L.) juice". Plant Foods for Human Nutrition 61 (2006): 187-192.

8. Barrera C., et al. "Phenolic profile of cane sugar derivatives exhibiting antioxidant and antibacterial properties". Sugar Technology (2020): 1-14.

9. Yao L H., et al. "Flavonoids in food and their health benefits". Plant Foods for Human Nutrition 59 (2004): 113-122.

10. Temelkova-Kurktschiev TS., et al. "Postchallenge plasma glucose and glycemic spikes are more strongly associated with atherosclerosis than fasting glucose and HbA1c level". Diabetes Care 23 (2000): 1830-1834.

11. Coutinho M., et al. "The relationship between glucose and incident cardiovascular events: a metaregression analysis of published data from 20 studies of 95,783 individuals followed for 12.4 years". Diabetes Care 22 (1999): 233-240. 
12. Pyörälä K., et al. "Glucose tolerance and coronary heart disease: Helsinki policemen study". Journal of Chronic Diseases 32.11-12 (1979): 729-745.

13. Hanefeld M., et al. "Risk factors for myocardial infarction and death in newly detected NIDDM: the Diabetes Intervention Study, 11-year follow-up". Diabetologia 39 (1996): 1577-1583.

14. Chiasson JL., et al. "Acarbose treatment and the risk of cardiovascular disease and hypertension in patients with impaired glucose tolerance: the STOP-NIDDM trial". JAMA 290 (2003): 486-494.

15. Wolever TMS., et al. "Determination of the glycaemic index of foods: interlaboratory study". European Journal of Clinical Nutrition 57 (2003): 475-482.

16. Lee JS., et al. "Comparative study of the physicochemical, nutritional, and antioxidant properties of some commercial refined and non-centrifugal sugars". Food Research International 109 (2018): 614-625.

17. Seguí L., et al. "Physicochemical and antioxidant properties of non-refined sugarcane alternatives to white sugar". International Journal of Food Science and Technology 50 (2015): 2579-2588.

18. Azlan A., et al. "Antioxidant activity, nutritional and physicochemical characteristics, and toxicity of minimally refined brown sugar and other sugars". Food Science and Nutrition 8 (2020): 5048-5062.

\section{Volume 5 Issue 6 June 2021}

\section{(C) All rights are reserved by Shaw Watanabe., et al.}

